\title{
DESIGN AND ANALYSIS OF ADVANCED WALKER CUM ROLLATOR
}

DOI : 10.36909/jer.ICIPPSD.15535

\author{
Dadaso D Mohite*, Harsh S Toraskar, Vibhor Chaturvedi, Neeladri S Bose
}

Department of Mechanical Engineering, Bharati Vidyapeeth (DU), COE, Pune, India

*Email: dadasomohite@gmail.com; Corresponding Author.

\begin{abstract}
Over the year's walker or rollator have helped many elderly people to overcome the barrier of dependency. As the age grows, the muscles and bones suffer weakening due to lack of calcium because of which person has to depend on others for their movement. This unwanted condition creates a bad physiological and psychological impact on the victim and slowly pulls them out of all possible types of interactions with society. Thus, to make the walker more users friendly, safe, and reliable, a new design or solution is proposed. This not only addresses the problem which is prevalent in the elderly section of society but also will be helpful to people with other disabilities. The proposed design of the walker is to increase the safety and movability of the user. The design of this walker is advanced as it consists of various sensors like an Obstacle sensor, GPS, and Load Sensor. In this paper, the design and analysis of an advanced walker cum rollator is elaborated, which significantly reduces the challenges faced by the elderly and specially challenged in day-today life.
\end{abstract}

Keywords: Design; Load Analysis; Mobility; Rollator; Stability; Walker

\section{INTRODUCTION}

Living normally is more difficult for those unfortunate individuals who lose the ability to stand on their own feet due to lower back or limb problems. This miserable condition, fortunately, has a solution as walkers or rollers which support the system to transfer the weight of the body to the ground through a mechanical structure instead of their legs. This reduces the pressure coming on the legs to a significant value. Furthermore, wheels are used in the design to enhance mobility. The Designers have proposed designs over time to improve Walker's performance and enhance the comfort of the victim. But no walker or roller contains brakes to stop it if necessary, instead feed on the motor itself is provided in opposite direction or it is done manually. But in the proposed design drum brakes are added to improve the safety of the user and controlling is also increased significantly. Sensors like GPS, Obstacle sensors, Load Sensors are also implied in this walker design to ease the comfort for the user. 
The study by Didymose Poovathumkal (Poovathumkal.,2019) describes the three major material choices are aluminium, mild steel \& cast iron. The study by M. Le and E.C. Jung (Le \& Jung.,2018); Nurul Ariffah Binti Hamidi (2012) suggested a three-wheeled design that can be used for climbing stairs. The study by E. Costamagnaa, et.al (2017) proposed an accurate method of calculating the combined stability of the patient and the walker frame by using the concept of combined Centre of Pressure ( $\left.\mathrm{COP}_{\text {sysem }}\right)$. The study by Merlet, J. P.(2011) provides a design for a walker cum rollator that uses a clutch system. The study by P. Médéric, et.al.(2017) describes the Kinematic designanalysis of the complex mechanical functions, geometrical parameter-optimization, and the actuator's capacity, dynamical simulation-evaluation of the mechanical design. The effective length of links of actuators for the device was determined through experimental measurements of interaction forces and hand movements were recorded during assisted sit to stand transfers of elderly patients. $\mathrm{R}$ Anslow and J Spicer (2001) Barry Deathe; et.al.(1996) experimented to find out the stability of the walker, none of the walking aid was found to be perfect. Gerard Lacey and Shane MacNamara (2000) described the design of advanced mobility aid and evaluation for people suffering from walking issues. Different types of sensors were used to gather data for navigational uses.

Based on this research, the existing solutions for walking aid significantly lack in fields like comfort, technology, and safety provided to the user. Thus, a better and more reliable design is hereby proposed to address the problems faced by the user. Comfort is improved by distributing equal weights on all the wheels (standing and sitting position) to enhance the combined stability of the walker. The technological advantage is offered by the addition of weight \& proximity sensors to provide real-time information mainly to specially challenged users. The brakes are inducted into the design to improve the safety of the user. Also, there is a scope for the addition of a clutch mechanism in the automated version of the hybrid walker cum rollator. The design that is presented is more ergonomic because of its multi-purpose serving capability. It is also convenient to use due to its less weight which provides better mobility and lesser strain to the body of the user.

\section{A. Anthropometric Measurements}

Anthropometry is the science of measurement and the art of application that establishes the physical geometry, mass properties, and strength capabilities of the human body. These Anthropometric measurements will help to design the proper walker as they will provide dimensions of different body sizes. Anthropometric measurements are used in many fields. For example, athletes understand that body size and composition are important factors in sports performance. Anthropometric data had been taken from the table mentioned below which enables designers to perceive exact measurement and material conditions for designing. Hence, the data considered in the design is corresponding to India. 
TABLE I

ANTHROPOMETRIC MEASUREMENTS OF WORLD [13]

\begin{tabular}{lcccccc}
\hline \multirow{2}{*}{\multicolumn{1}{c}{ Population }} & \multicolumn{2}{c}{ Sitting Height } & \multicolumn{2}{c}{ Height } & \multicolumn{2}{c}{ Foot Length } \\
\cline { 2 - 7 } & Female & Male & Female & Male & Female & Male \\
\hline Japan & 760 & 813 & 1476 & 1585 & 204 & 224 \\
France & 797 & 853 & 1481 & 1607 & 209 & 237 \\
North Africa & 770 & 807 & 1454 & 1527 & 217 & 237 \\
West Africa & 720 & 734 & 1402 & 1507 & 206 & 234 \\
South America & 783 & 846 & 1478 & 1608 & 205 & 227 \\
North America & 803 & 860 & 1494 & 1627 & 217 & 239 \\
Spain and Portugal & 780 & 804 & 1465 & 1533 & 198 & 228 \\
North India & 750 & 800 & 1412 & 1535 & 199 & 222 \\
India & 780 & 814 & 1469 & 1506 & 199 & 218 \\
Eastern Europe & 814 & 840 & 1502 & 1615 & 217 & 237 \\
Northern Europe & 823 & 880 & 1541 & 1668 & 217 & 232 \\
Australia & 810 & 860 & 1521 & 1607 & 212 & 244 \\
Southeast Europe & 790 & 830 & 1485 & 1595 & 212 & 237 \\
Central Europe & 803 & 870 & 1518 & 1575 & 212 & 232 \\
Africa & 750 & 790 & 1442 & 1545 & 202 & 232 \\
Middle East & 780 & 813 & 1496 & 1582 & 214 & 232 \\
South India & 723 & 743 & 1351 & 1485 & 194 & 217 \\
China & 720 & 770 & 1406 & 1590 & 204 & 224 \\
Southeast Asia & 730 & 763 & 1402 & 1495 & 201 & 214 \\
\hline
\end{tabular}

Based on height and weight, the different candidates are chosen and give an idea about the anthropometric measurements of people and will help further in the design of the Walker. Based on the input measurements the material suitable for the walker is selected. Further, it may help to give an idea of the market the walker is concerned about.

\section{TABLE II}

DETAILS OF SELECTED CANDIDATE

\begin{tabular}{ccc}
\hline Person & $\begin{array}{c}\text { Weight of the } \\
\text { Person }\end{array}$ & $\begin{array}{c}\text { Height of the } \\
\text { Person }\end{array}$ \\
\hline Candidate 1 & 80 & $5 ' 5^{\prime}$ \\
Candidate 2 & 84 & $5^{\prime} 10^{\prime}$, \\
Candidate 3 & 52 & $4^{\prime} 11^{\prime}$, \\
\hline
\end{tabular}

Based on weight and height three different candidates were studied. This data helped with the design of the walker as it shows the various measurement requirements of different persons.

\section{METHODOLOGY}

The key insights had been taken from the existing problems by identifying every aspect of the walker and ensuring the possibility of improving the current model and its function. The basic problems 
with existing walkers have been addressed in the design to increase the convenience of the users. The material is selected based on the design and load conditions on the walker. The CAD Modeling is done by using SOLIDWORKS software and lastly, the model is analyzed with different load conditions using ANSYS software. The design of this walker is modified by the addition of various sensors mainly the Obstacle sensor, GPS, and Load Sensor, which will increase the safety of and reduces the challenges faced by the elderly.

\section{DESIGN AND ANALYSIS OF WALKER}

The design calculations and analysis of the walker can be done by considering different load conditions on the walker and fulfilling the requirement of the user. The different materials can be used for the walker. But, making a lightweight walker and satisfy the loading condition is an essential part of the design. Table III shows the different materials and their properties which can be used for the walker.

TABLE III

MATERIALS AND ITS PROPERTIES USED FOR WALKER

\begin{tabular}{lccc}
\hline Material & $\begin{array}{c}\text { Tensile Strength } \\
\text { (Mpa) }\end{array}$ & $\begin{array}{c}\text { Yield Strength } \\
\text { (Mpa) }\end{array}$ & $\begin{array}{c}\text { Density } \\
\text { (G/Cc) }\end{array}$ \\
\hline Magnesium Alloy & 230 & 160 & 1.81 \\
Aluminum Alloy & 300 & 241 & 2.7 \\
Steel & $400-550$ & 250 & 7.8 \\
\hline
\end{tabular}

A. Design calculations for Walker cum Rollator

The material for the walker is an Aluminium 6061-T6 pipe of thickness $1.5 \mathrm{~mm}$ is considered. The Allowable tensile strength of the selected material is $227 \mathrm{~N} / \mathrm{mm}^{2}$. The reactions on each wheel are $3 \%$ of axial load which is negligible. The product is designed for a $120 \mathrm{~kg}$ person. According to research most of the load is transmitted to the frontal region of the walker. The load transmitted through the body is $90 \%$ of $120 \mathrm{~kg}(1177.2 \mathrm{~N})$ i.e. approximately $1060 \mathrm{~N}$. The front part walker bears the maximum load up to around 65 to $70 \%$ and the rear wheel bears 30 to $35 \%$ while walking. But there is a chance of getting more load on the backside while standing hence it is calculated according to full load condition as the product works as a wheelchair also.

To find out the diameter of the pipe front section is selected as it bears the maximum load. The assumption is made that the load transmits equally from both the vertical components of the frame. The maximum bending moment is calculated by shear force diagrams and bending moment diagrams. And with the help of bending Moment Equation we can calculate further the diameter of the shaft: 


$$
\frac{\mathrm{E}}{\mathrm{R}}=\frac{\mathrm{M}}{\mathrm{I}}=\frac{\sigma}{\mathrm{y}}
$$

Where, $\sigma$ is bending stress, $\mathrm{y}$ is the distance from the neutral axis, $\mathrm{M}$ is bending moment, $\mathrm{I}$ is the second moment, E is Young's modulus of elasticity and $\mathrm{R}$ is the radius of curvature.

i. Maximum bending moment, $\mathrm{M}=78175 \mathrm{~N}-\mathrm{mm}$

ii. Allowable Stress, $\sigma_{b} \frac{\mathrm{M} \times \mathrm{Y}_{\max }}{\mathrm{I}}$

iii. Moment of Inertia, $I=\frac{\pi d^{3} t}{8}$

iv. Distance from Neutral axis, $Y_{\max }=\frac{d}{2}$

v. Diameter, $d=21.0385 \mathrm{~mm}$, The nearest standard diameter is $25 \mathrm{~mm}$ i.e. 1 inch is selected from the manufacturer's catalogue.

\section{B. Stability and mobility of the Walker}

The stability and mobility of the walker can be defined by using the force diagram to understand the different forces acting on the walker. As per medical norms, the walker is required to be adjustable in height, such that the elbow flexion is 30 degrees. Else the gait and standing stability is assumed to be impaired. [10]. Walker Tipping Index (WTI) indicates how likely the model is to tip over due to vertical and horizontal forces that are acting on the body of the walker. Further, normalizing the tipping index with respect to the bodyweight that is being transferred on the device.

\section{i. Centre of force for walker}

The centre of force is the force that is radially pointing and the magnitude is dependent on the distance from the source. Examples of central forces are gravitational force, electrostatic forces, and spring force. It is used to define the stability of the body. The centre of the force is calculated by considering the load which is transmitted to the frontal and rear part of the walker. It is assumed that $F_{1}$ and $F_{2}$ are the loads is transmitted towards the front end of the walker and, $F_{3}$ and $F_{4}$ are the loads transmitted to the rear part of the walker. It can be determined that about $65 \%$ of the load is transmitted towards the front end and the remaining $35 \%$ of the load is trans mitted to the rear part of the walker.

$$
\begin{aligned}
& \mathrm{F}_{1}=\mathrm{F}_{2}=689.0 \mathrm{~N} \quad(65 \% \text { of the load transmitted }) \\
& \mathrm{F}_{3}=\mathrm{F}_{4}=371.0 \mathrm{~N} \quad(35 \% \text { of the load transmitted })
\end{aligned}
$$

The centre of force in the horizontal direction $\mathrm{COF}_{\mathrm{X}}$ and vertical direction $\mathrm{COF}_{\mathrm{Y}}$ is calculated by: 


$$
\begin{gathered}
\operatorname{COF}_{X}=\frac{W_{12}\left(F_{1}-F_{2}\right)+W_{43}\left(F_{4}-F_{3}\right)}{2\left(F_{1}+F_{2}+F_{3}+F_{4}\right)} \\
\operatorname{COF}_{y}=\frac{L\left(F_{1}-F_{4}\right)+L\left(F_{4}-F_{3}\right)}{2\left(F_{1}+F_{2}+F_{3}+F_{4}\right)}
\end{gathered}
$$

Where, Depth of walkers, $\mathrm{L}=1030.5 \mathrm{~mm}$; Distance between the front wheel and rear wheels, $\mathrm{W}_{12}=$ $\mathrm{W}_{43}=600 \mathrm{~mm}$. Solving the above equations, $\mathrm{COF}_{\mathrm{X}}=0 \mathrm{~mm}$ and $\mathrm{COF}_{\mathrm{Y}}=77.287 \mathrm{~mm}$. Based on calculations the design of the walker can be interpreted and thus the walker can be further analyzed.

ii. Walker Tipping Index (WTI)

The tipping force $\left(\mathrm{F}_{\mathrm{t}}\right)$ and the force applied in the vertical direction $\left(\mathrm{F}_{\mathrm{v}}\right)$ on the handle of the walker by the user also considering the perpendicular distance are used to determine Walker's Tipping index. Vertical $\left(\mathrm{F}_{\mathrm{y}}\right)$ and anterior $\left(\mathrm{F}_{\mathrm{x}}\right)$ forces that are acting on the walker frame is illustrated in Fig.1. Anterior force $\left(\mathrm{F}_{\mathrm{x}}\right)$ creates a moment of force when it is applied to the handles of the walker. This force will incite the walker to tip forward.

To avoid the walker from tipping forward, this forward force $\left(F_{x}\right)$ that creates a moment should be less than the moment created by vertical force $\left(\mathrm{F}_{\mathrm{y}}\right) . \mathrm{F}_{\mathrm{y}}$ is applied at a distance of $\left(\mathrm{r}_{\mathrm{p}}\right.$ ) (perpendicular distance from the front end of the walker). By using data obtained from the centre of pressure and forces acting upon the walker frame, a WTI curve can be generated which can give an idea of the stability of the walker in all four directions.

The four directions of the walker are represented as,

$$
\begin{array}{ll}
W T I_{\text {forward }} & : \text { Over front arms } \\
W T I_{\text {backward }} & : \text { Over the rear arms } \\
W T I_{\text {prosthetic sidex }} & : \text { Ipsilateral position (beside the prosthetic leg) } \\
W T I_{\text {intact sidex }} & : \text { Contralateral position (Beside the intact leg). }
\end{array}
$$

The stability of the walker will be relatively lower if the WTI curve is high.

$$
W T I=\frac{F_{x} \times \text { walker height }}{F_{y} \times r_{p}} \times 100 \%
$$

Where $F_{y}$ is a vertical force, $F_{x}$ is the horizontal force acting perpendicular to the axis, $r_{p}$ is the perpendicular distance of the walker (centre of pressure) to the axis. The walker height is the distance between the handles of the walker to the floor.

The WTI is defined as follows: 


$$
W T I=\frac{\left(\sum F_{t} \times R_{t}\right)}{\left(\sum F_{v} \times R_{v}\right)}
$$

Where, the distances of $\left(F_{v}\right)$ and $\left(F_{t}\right)$ from the tipping axis are $\left(R_{v}\right)$ and $\left(R_{t}\right)$, respectively.

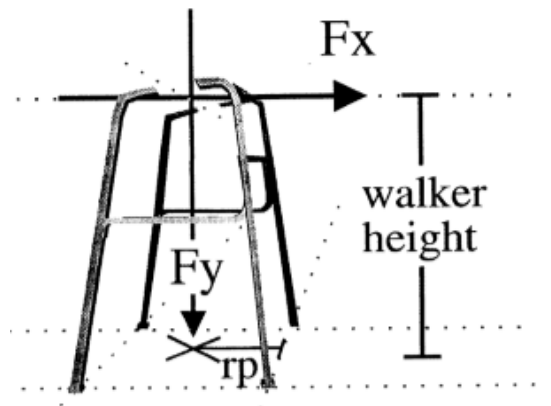

Fig.1. Representation of $\left(\mathrm{F}_{\mathrm{x}}\right)$ and $\left(\mathrm{F}_{\mathrm{y}}\right)[10]$

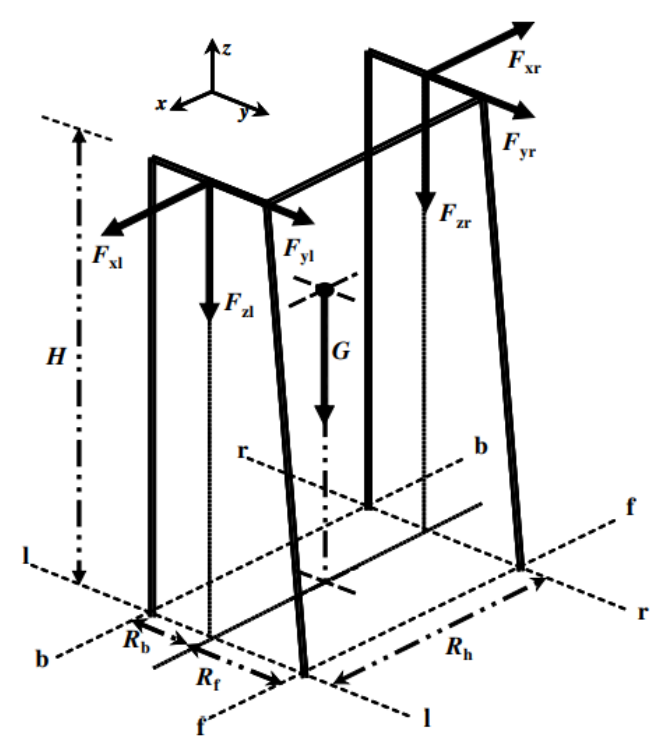

Fig.2. Free Body Diagram of walker [19]

\section{iii. Height of walker}

The stability is dependent on Walker Tipping Index and the height of the walker is decided based on WTI [10]. The user body weight is also a deciding factor in the adjustment of the height of the walker. This walker is designed for height suitable for the user and also to not affect the stability of the walker.

\section{Computer-Aided Design Model for Walker cum Rollator}

The CAD Model gives the idea about the prototype and due to its loading conditions can be analyzed. CAD Model of this walker is prepared on SOLID WORKS modelling software. The material properties became critical for testing how the design will behave under different loading conditions, before investing time and money into the construction of a real prototype. The CAD model is designed to suit the safety of the user and to ease the problem of the elderly section of society. This design has been done so that no toppling takes place during the usage of this walker. 


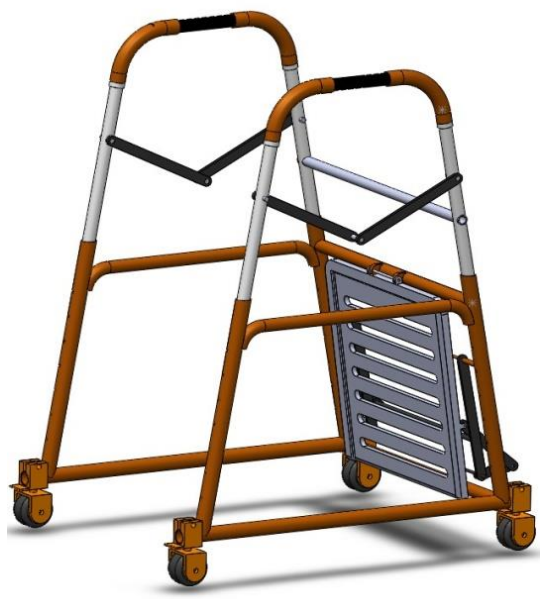

Fig.3. CAD Model of Walker

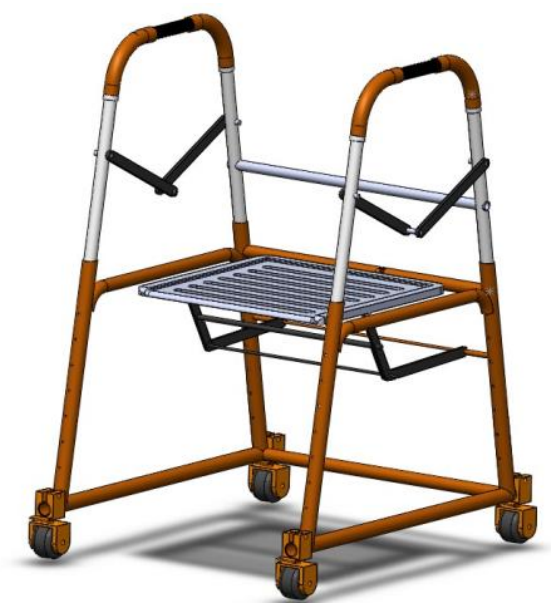

Fig.4. Sitting Position in Walker cum Rollator

\section{Analysis of Walker cum Rollator}

The analysis was performed on ANSYS software considering the material that was used for the manufacturing of the product and applied 1177.2 $\mathrm{N}$ loads on it, to get the results for maximum deformation and stress at critical point. The analysis was purely based on the safety conditions of the user and the sustainability of the product. TABLE IV shows the properties of Aluminium 6061-T6.

TABLE IV

MATERIAL PROPERTIES

\begin{tabular}{lcc}
\hline \multicolumn{1}{c}{ Properties } & Unit & Magnitude \\
\hline Density & $\mathrm{g} / \mathrm{cc}$ & 2.7 \\
Poisson's Ratio & - & 0.33 \\
Tensile Yield Strength & $\mathrm{MPa}$ & 276 \\
Ultimate Tensile Strength & $\mathrm{MPa}$ & 310 \\
Modulus of Elasticity & $\mathrm{GPa}$ & 68.9 \\
\hline
\end{tabular}

a) Analysis of Walker cum Rollator for Seated Position

The seat of the walker cum rollator is designed for an individual weighing a maximum of $120 \mathrm{~kg}$ and who is at an average height of between $5.5 \mathrm{ft}$ and $6 \mathrm{ft}$ tall. The seat has been positioned in such a way that when an individual would sit upon it, the load will be equally distributed a mongst all four of its wheels, maintaining a suitable centre of gravity so that the chances of rollover is 
minor and wear of all the parts of the walker cum rollator occurs uniformly and gradually. In fig. 5, A (Blue highlight) are two fixed supports, and point B (red highlight) is the region where the load is to be applied. The respective deformation and maximum principal stress are noted from the result.

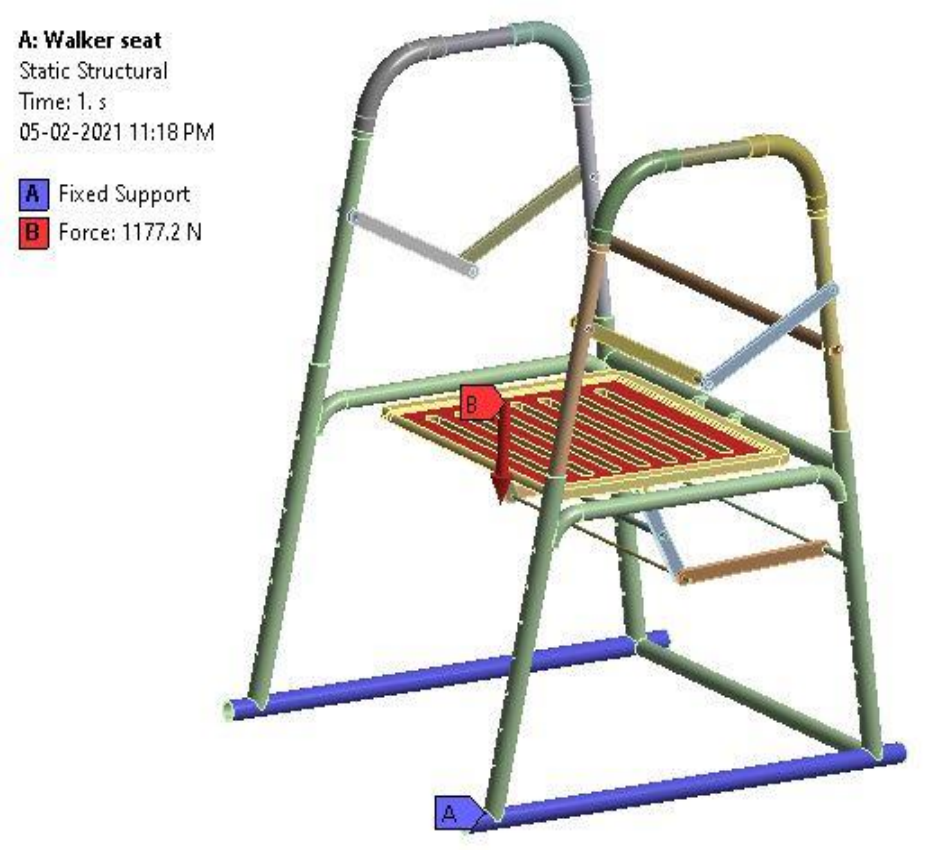

Fig.5. Force Analysis of Walker cum Rollator for Seated Position

A load of $1177.2 \mathrm{~N}$ is applied to the seat. The maximum deformation is observed at the front end of the seat. The maximum deformation after the analysis is $21.975 \mathrm{~mm}$. This level of deformation does not occur instantly though the time in which the load is applied over the seat is swift. The deformation in the design can be reduced by adding a bar across the seat without much increase in the weight or by adding appropriate supports to the front end of the seat. 


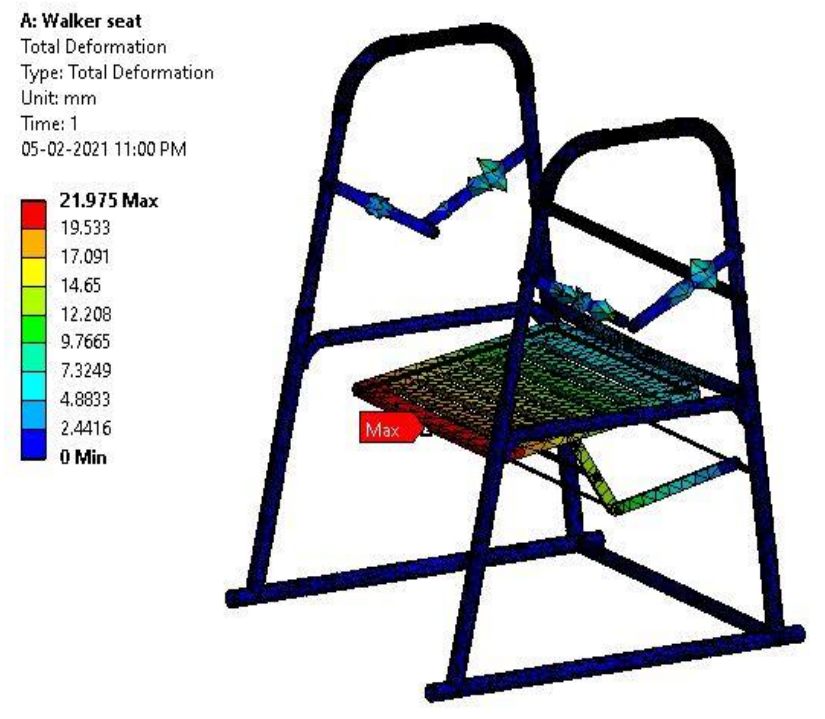

Fig.6. Total Deformation in walker seat

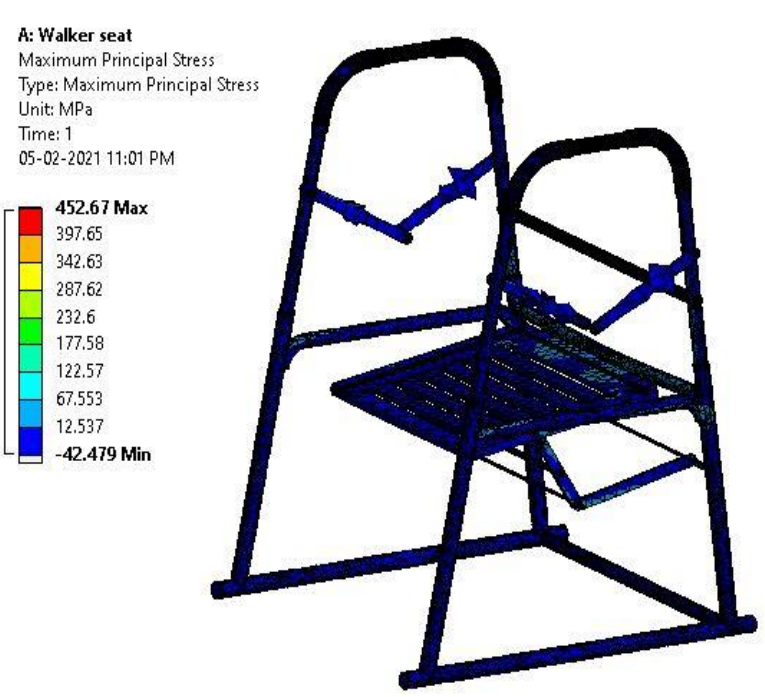

Fig.7. Maximum Principal Stress in the walker for Seated Position

From Fig. 6 and Fig. 7, it is concluding that the maximum principal stress undergone when an individual would take a seat. From fig. 6, the total deformation in the walker is $21.975 \mathrm{MPa}$ and from fig.7, the maximum principal stress was turned out to be $452.67 \mathrm{MPa}$.

\section{b) Analysis of Walker cum Rollator for Standing Position}

In the case when the model will have to be used as a walker, the seat is made such that it can be folded downwards, allowing the individual to stand in between like any other normal walker and use it comfortably. While performing this analysis, the factor being such that the load will be applied on the handles gradually rather than instantly is considered. In fig. 8, A (Blue highlight) are two fixed supports and, point B and C (red highlight) are the regions where the load is to be applied. Again, the respective deformation and maximum principal stress are noted from the result. 


\section{B: Walker handle Static Structural \\ Time: 1.5 \\ 06-02-202112:29 AM \\ A Fixed Support \\ B Force: $588.6 \mathrm{~N}$ \\ C Force $2: 588.6 \mathrm{~N}$}

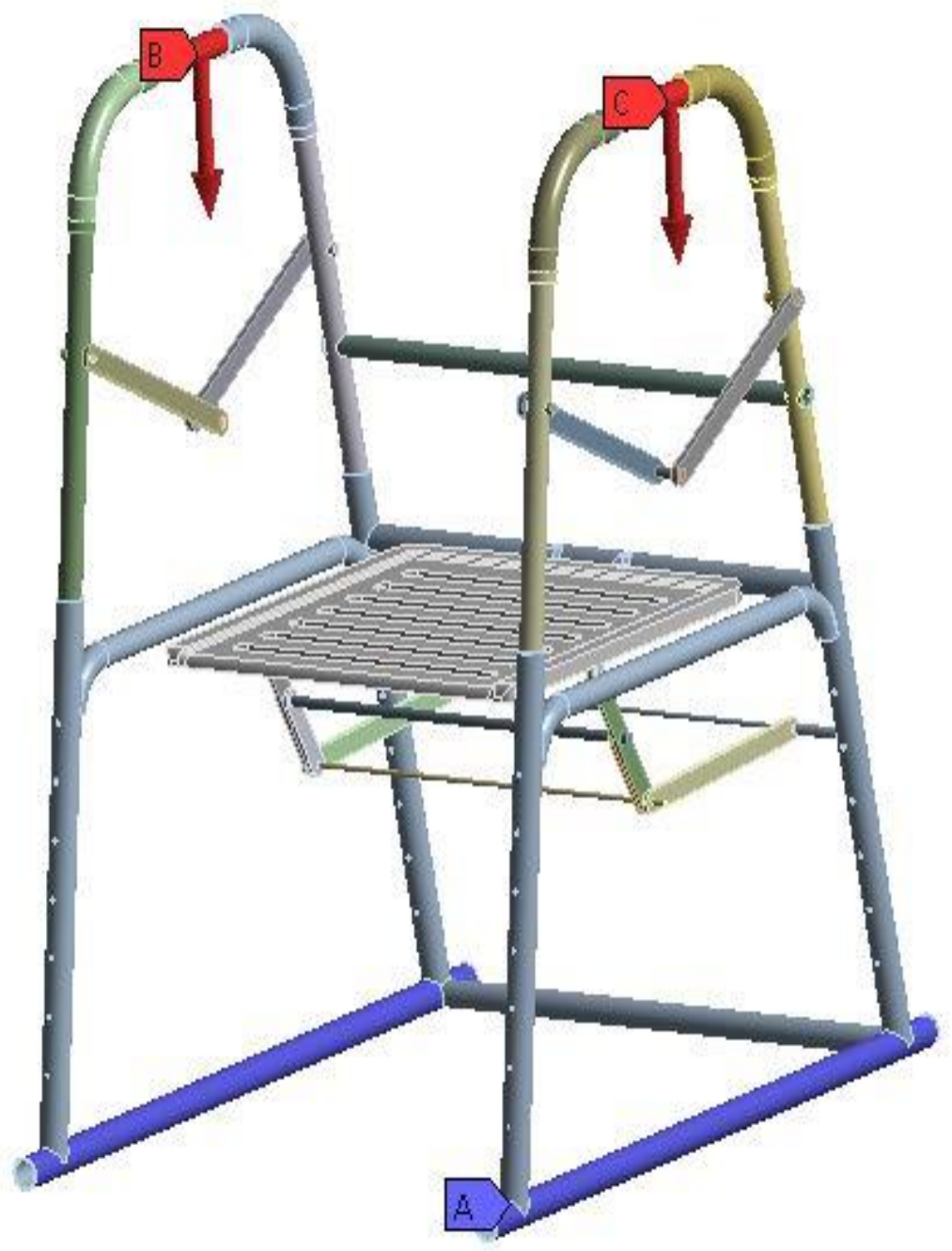

Fig.8. Force Analysis of Walker cum Rollator for Standing Position

From fig. 8 and fig. 9, the total deformation occurring on the handle is $41.495 \mathrm{~mm}$ and the maximum principal stress on the handle is $486.7 \mathrm{MPa}$. It can conclude that, from the above results design of the walker cum rollator is reliable. 


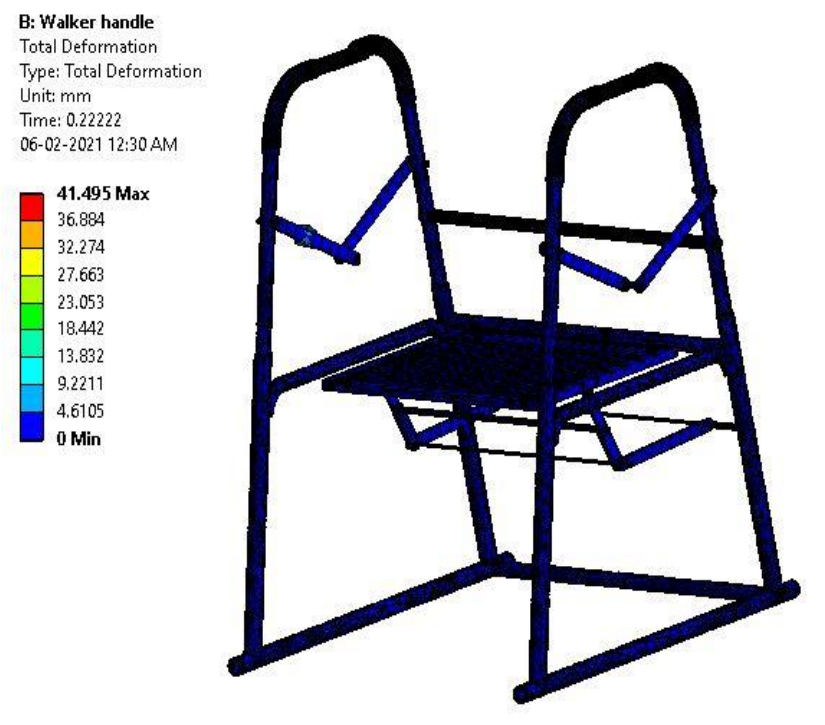

Fig.9. Total Deformation in the handle section

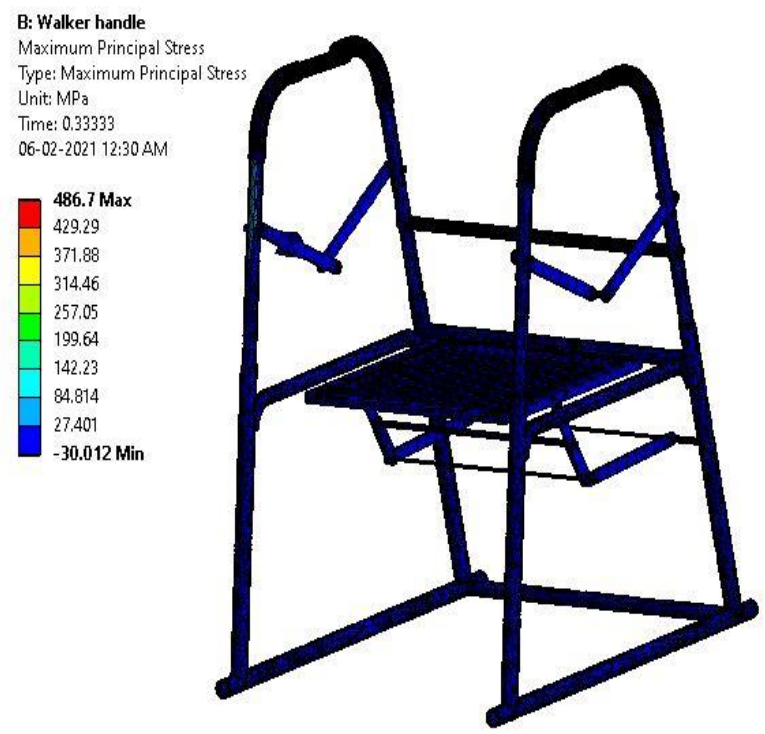

Fig.10. Maximum Principal Stress in the walker for Standing Position

\section{E. Advancement in Design of Walker}

The various sensors are added to this walker so that the blind or visually impaired can travel safely. For instance, the obstacle sensor may protect the user from any accident, and with the help of GPS sensors the user's locations can be easily accessible to family members which increases the safety of the user.

\section{a) Obstacle Sensor (Proximity Sensor)}

The built-in IR transmitter and receiver in the Infrared Obstacle Sensor Module send out IR energy and search for reflected IR energy to detect the presence of any obstacle in front of the sensor module. The detection range can be adjusted using an onboard potentiometer. When it comes into contact with an obstacle, the sensor will finally stop working.

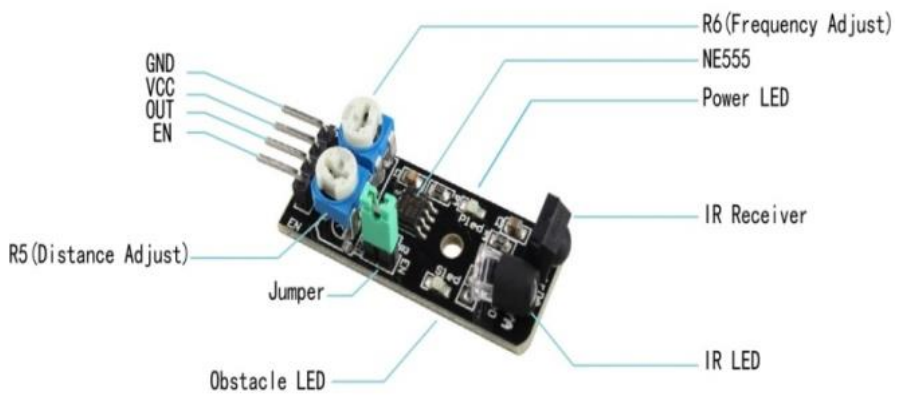

Fig 11 Obstacle Sensor [14]

b) Global Positioning System (GPS) 
These sensors are receivers with antennas that use a satellite mode of communication to provide information of velocity, timing and precise location via a network of orbiting satellites in lower earth orbit. GPS does not only help to track the location of the device also it may transmit the location of the user to any other devices with data service according to the situation.

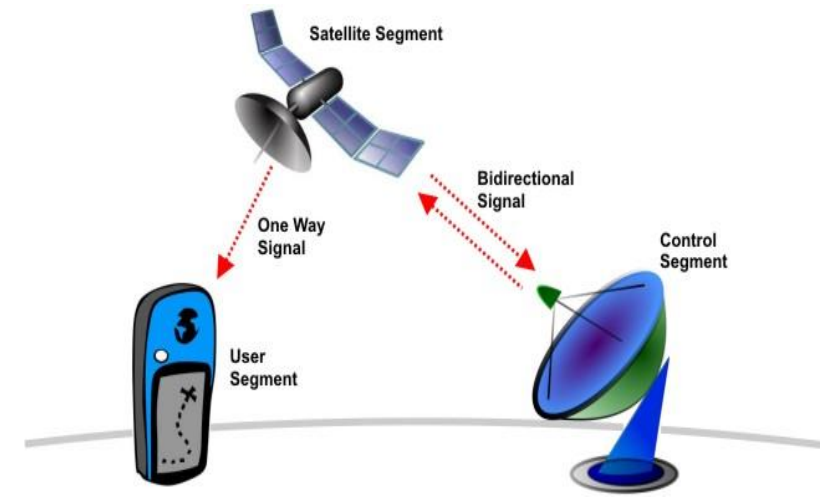

Fig 12 Global Positioning System (GPS) [15]

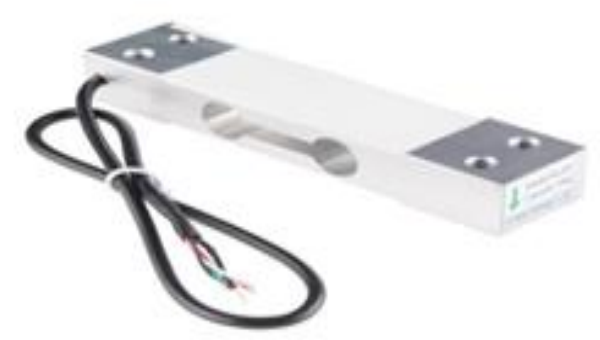

Fig 13 Load Sensor [16]

\section{c) Load Sensor}

Load sensors can be used in the walker with the help of the input of load cells, load sensors can be used in the walker. A force transducer is a load cell. It turns a force such as tension, compression, strain, or torque into a tangible and structured electrical signal. The electrical signal changes proportionally to the force applied to the load cell. Eventually, the alarm can also be compiled with this setup. Whenever the given weight on the walker is exceeded the alarm will start and warned the user about weight being exceeded beyond operational limits.

\section{CONCLUSION}

Through this research paper, the aim is to reach out to the elderly section with a walking disability and provide them with a better lifestyle and independence. The design is done with the aim of it being as ergonomic, light, and user friendly as possible. The main advantage of making this design of walkers is that most of the products available in the market are just for walking and thus the people have to invest in other products along with the wheelchairs, rollator, etc. This design is made such that it serves two purposes of it being a walker and rollator with adjustable height by considering anthropometric measurements of the user. If these types of walkers roll out in the market of today's times it will have a huge impact on the society of elderly people, who will not only be helped by these convenient walkers but also be able to lead easy and comforting lives. Lastly, this will also help other developers to improve the existing models further in other to provide our elder generation with the respect and comfort they deserve.

\section{REFERENCES}


Didymose Poovathumkal, "A Review on Walker Material and Design," in the International Research Journal of Engineering and Technology (IRJET), Vol. 06, Issue 05, May 2019

M. Le and E.-C. Jung, "Tri-Wheel Stairwalker: Design Proposal Of Walker Usable At District Using Stairway", International Design Conference- Design 2018, pp. 2275-2286, http//doi.org/1021278/idc.2018.0447

E.Costamagnaa, S. B. Thies, L.P.J. Kenneya, D. Howardb, A. Liu A and D. Ogden, "A Generalisable Methodology for Stability Assessment of Walking aid Users", Medical Engineering and Physics, 47, 167-175, doi:101026/.medengphy.2017.06.013

F. Nickpour and C. O'Sullivan, "Designing an Innovative Walking Aid Kit: A Case Study of Design in Inclusive Healthcare Products," Springer International Publishing Switzerland, pp.45-54, 2016

Nurul Ariffah Binti Hamidi, "Design and Fabrication of Adjustable and Portable 4-Legs Walker", University Malaysia Pahang, January 2012.

MerletJP, "Preliminary Design of ANG, A Low-Cost Automated Walker For Elderly," New Trends in Mechanism Science, Mechanisms and Machine Science, Vol. 5, Springer, Dordrecht. https//doi.org/10.1007/978-90-481-698-0_61

P. Médéric, V. Pasqui, F. Plumet and Ph. Bidaud, "Design of a walking-aid and sit-to-stand transfer assisting device for elderly people," Conference: 15th CISM-IFToMM, 2004.

R Anslow, N Weyman, et. al., "Stability And Manoeuvrability of Wheeled Walking Frames", Physiotherapy, Volume 87, Issue 8, August 2001, Pages 402-412, http://org/101016/S00319406(05)65459-4.

Gerard Lacey and Shane MacNamara, "User Involvement in Design And Evaluation of A Smart Mobility Aid," Journal of Rehabilitation Research and Development, Vol. 37, No. 6, November/December 2000, Pages 709-723.

A. Barry Deathe, Richard D. Pardo, David A. Winter, Keith C. Hayes, Jennifer Russell-Smyth, “Stability Of Walking Frames," Journal of Rehabilitation Research and Development, Vol. 33 No. 1, February 1996, Pages 30-35

Yeh Po-Chan, and Leung Cherng-Yee, "Using Walker during Walking: A Pilot Study for Healthy 
Elder”, Work 41 (2012), DOI: 10.3233/WOR-2012-0434, IOS Press 2081-2085, 0434-2081.

Margaret P O'Hare, Shona J Pryde, Jacqueline H Gracey, "A Systematic Review of the Evidence For the Provision of Walking Frames for Older People”, 12 Nov 2013s, pp. 11-23, http://doi.org/10.1179/1743288X12Y.0000000036.

WHO, “WHO,”2342015.[Online].Available:https://www.who.int/childgrowth/publications/deonis_h abicht_1996/en/. [Accessed 3012021 ].

Google,3012017. [Online]. Available:https://www.electronicscomp.com/image/cache/catalog/loadcell-india-800x800.jpg. [Accessed 30 January 2021].

Technews.365.info, "Google," 233 2018. [Online]. Available: https://technews365.info/wpcontent/uploads/2013/08/GPS-technews365.jpg.[Accessed 3012021 ].

Google,3012017.[Online].Available:https://www.electronicscomp.com/image/cache/catalog/loadcell-india-800x800.jpg. [Accessed 30 January 2021].

Xiuyun Liu, Yong Hu, John C Y Leong, “A gait stability investigation into FES-assisted paraplegic walking based on the walker tipping index," Journal of Neural Engineering, Vol. 6, 2009. doi:10.1088/1741-2560/6/6/066007

D.D. Mohite, Sagar Mollah, Shagoria Bagchi, and Aditya Narayain Singh, "Design of Hybrid Rollator cum Walker for Elderly: Review on Literature", The International Journal of Analytical and Experimental Model Analysis, Vol. XII, Issue I, 2020.

$* * * * * * * * * * * * * * * * *$ 